\title{
The effect of internalization and other psychologic factors on the remission and severity of wheeze in children
}

\author{
Caroline A. Feitosa ${ }^{1}$, Darci N. Santos ${ }^{1}$, Maurício L. Barreto ${ }^{1} \&$ Laura C. Rodrigues $^{2}$ \\ ${ }^{1}$ Institute of Collective Health, Federal University of Bahia - ISC/UFBA, Salvador, Brazil; ${ }^{2}$ London School of Hygiene and Tropical Medicine - \\ LSHTM, London, UK
}

To cite this article: Feitosa CA, Santos DN, Barreto ML, Rodrigues LC. The effect of internalization and other psychologic factors on the remission and severity of wheeze in children. Pediatr Allergy Immunol 2016: 27: 398-403.

\section{Keywords}

asthma; behavior problems; childhood asthma; internalization; remission; Social Changes, Asthma and Allergy in Latin

America; severity; wheeze

\section{Correspondence}

Caroline A. Feitosa, Institute of Collective Health, Federal University of Bahia - ISC/ UFBA, Salvador 40110040, Brazil

Tel.: +557132837478

Fax: +55 7193695744

E-mail: feitosacaroline@gmail.com

Accepted for publication 1 February 2016

DOI:10.1111/pai.12545

\begin{abstract}
Background: Asthma prevalence in Latin America is high and continues to increase. There is evidence that the psychologic characteristics of the child are associated with greater asthma morbidity. This study aimed to investigate the independent effect of internalizing/externalizing problems on two asthma/wheeze outcomes: (i) remission and (ii) progression to severity on Latin American children with mild asthma symptoms at baseline.

Methods: This was a prospective study in a cohort of 371 asthmatic children living in a poor urban area in Salvador, Brazil. The psychologic characteristics of the child were assessed using the Child Behavior Checklist (CBCL), and wheezing was defined using the ISAAC questionnaire at the start and end of follow-up. A multiple logistic regression model with random effects was used to examine the association between the psychologic components and both outcomes.

Results: Remission of symptoms of wheeze was observed among 229 (61.73\%) children. Remission was $56 \%$ lower among children with internalizing problems $(\mathrm{OR}=0.54,95 \%$ CI $0.33-0.87, \mathrm{p}=0.01)$. In addition, we found that $19(8.76 \%)$ of the children acquired severe symptoms during follow-up and there was strong evidence of the effect of internalizing problems in increasing the risk of progression to severe wheeze symptoms $(\mathrm{OR}=4.03,95 \%$ CI $1.39-11.70, \mathrm{p}=0.01)$.

Conclusions: Children with internalizing problems but not externalizing had less remission of wheezing, and a higher risk of acquiring severe symptoms. These results highlight the importance of psychologic care for children with asthma, to improve the prognosis of this condition.
\end{abstract}

Asthma is the most common chronic disease in childhood. It is an important public health problem not only because of the increase in its prevalence in recent decades, but also due to the high costs to the health system and the functional losses associated with the condition. In Brazil, the costs with the management of asthma have increased, reaching 51 million dollars per annum in 2006, the third largest expense with a single disease (1-3). Also, uncontrolled asthmatic patients account for higher healthcare expenditures than controlled patients (4).

There is increasing evidence suggesting a link between psychologic stress and the biological system, affecting the

\footnotetext{
Abbreviations

SCAALA, Social Changes, Asthma and Allergy in Latin America; ISAAC, International Study of Asthma and Allergies in Childhood; $\mathrm{CBCL}$, Child Behavior Checklist; AOR, Adjusted odds ratio.
}

disease progression and disease management in different stages of the life course (5-7). Independent of the direction of causality, recent studies have been frequently shown evidence that the comorbidity between depression/anxiety and other psychologic symptoms with asthma leads to less adhesion to treatment (8-10), higher burden of symptoms (11), more frequent hospitalization and for longer periods $(12,13)$, and more days of wheezing per year (13) and depression was also found to be associated with higher mortality per asthma in adults (14). It has also been previously reported that children with elevated levels of behavior problems had limited asthma problem-solving skills (13). However, only a few studies have investigated the relationship between psychologic disorders and the course and burden of asthma symptoms $(11,13)$, with no studies been carried out in Latin America, where there is a high prevalence of current wheeze and an increasing need for 
studies concerning risk factors for asthma, and more specifically for non-atopic asthma (15-17).

This study has two main aims, both seeking to understand the role of this psychologic factor on the course of the disease: (i) to identify the effect of behavioral problems on the remission of wheezing in asthmatic children followed for 2 years, and (ii) to investigate how these behavioral factors affect the progression to severity among those children with non-severe wheezing symptoms at baseline.

\section{Methods}

\section{Study design}

This is a prospective cohort study, part of the SCAALA Project (Social Changes, Asthma and Allergies in Latin America). The project is composed of a set of research activities that have been taking place in Brazil and Ecuador since 2004, and details of the study design and methods are described elsewhere $(17,18)$.

Salvador is a large Brazilian urban center located in the northeast region, the poorest region of the country. The original study population was composed of 1445 children aged 4-11 years at baseline, who were randomly selected using multistage sampling from 20,000 households from varying areas of the city. A first home visit was performed between May and October of 2005, and the occurrence of wheezing was defined through parental reporting (18). From the initial sample of 1445 children, 417 presented wheeze in the last 12 months. All children who presented wheezing in 2005 were included in this cohort. A second visit was performed in 2007, and the occurrence of wheezing was re-assessed. There were 18 missing data regarding the psychosocial assessment, and 28 losses of follow-up until the second assessment.

\section{Measures}

Remission and severity of persistent wheeze

An adapted questionnaire from the International Study of Asthma and Allergies in Childhood (ISAAC) was used to assess the occurrence of wheezing and other respiratory symptoms in both periods. The remission of wheezing was present when the answer for the question 'has your child had wheezing in the last 12 months?' was negative at the second assessment (follow-up). Wheezing is characterized by continuous and musical breath sounds that can appear during both inhalation and exhalation. Severity of symptoms was defined based on the presence of the following symptoms: more than 12 wheezing episodes/year, wheezing and breathlessness resulting in difficulty in speaking, and more than 1 day of disturbed sleep/week due to asthma. This definition of severe symptoms using ISSAC items was previously reported as in agreement with other clinical classifications of asthma severity (19).

\section{Psychologic characteristics of the child}

The psychologic characteristics of the child were assessed through parental reporting using the Child Behavior Checklist (CBCL). This instrument provides a broad coverage of the main psychopathologic symptoms in childhood and adolescence, and it is the most widely used in epidemiological studies worldwide, translated to more than 40 societies with excellent reliability (20, 21 ). The checklist comprises a total of 118 items organized into eight subscales, which are usually reorganized into two dimensions: 'internalizing problems' (withdrawal, somatic complaints, anxiety/depression) and 'externalizing problems' (aggressive and rule-breaking behavior). Both dimensions and the remaining scales (social problems, thought problems, attention problems) account for the total score for behavior problems. The total crude amount of points is weighted and converted into a $\mathrm{T}$ score, and children were considered positive for total behavior problems when scoring more than 64 points. This scoring strategy has been used in several multicultural studies, providing greater sensitivity in identifying cases (20), including validation research in Brazil, where this cutoff presented good sensitivity $(87 \%)$, discriminating $95 \%$ of the moderate cases and $100 \%$ of the severe cases (22). Although the internalization and externalization components are independently scored, the occurrence of both profiles is largely described as concurrent $(8,21)$. Also, as the total problem component is a summary of the amount of answers for all subgroups of the instrument, and both internalization and externalization components account for a large proportion of the number of items in the instrument, most but not all children with internalization or externalization would also be positive for total problems. Because of these intrinsic proprieties of the instrument, and the high proportion of overlapping between the scales, we decided to generate a new variable with four levels of classification: (i) non-exposed, with those children with no problems at all; (ii) children who had only externalization problems; (iii) children with internalization problems only; and (iv) children with internalization, externalization, and other problems. Using this approach, it was possible to investigate the independent effect of internalization and externalization on asthma outcomes.

Potential confounders and other variables

Data on family composition, sex, the child's age, level of maternal education, smoking habits, and other socio-demographic characteristics of the household were obtained through a standardized questionnaire.

Atopy was defined through the measure of serum allergenspecific IgE which was available for $95.8 \%$ of the children. It was obtained through serological examination, according to serum levels of allergen-specific IgE to D. pteronyssinus, $B$. tropicalis, B. germanica, and P. americana using the ImmunoCAP assay (Pharmacia, Uppsala, Sweden). The lower detection limit for allergen-specific IgE was 0.70 kilounit $(\mathrm{kU}) / 1$.

\section{Data management and analysis plan}

The data were double-entered into the ADM Software, version 2001 ASEBA. Vermont, USA, to reduce consistency errors. The effect of the clusters (micro areas) was taken into account using a multiple logistic regression model with random effects. The $\mathrm{OR}$ and correspondent CI were estimated for the association between the remission of wheezing and internalization, externalization, and other behavior problems. The same strategy wad 
used to examine the association between the psychologic components and the acquisition of severe symptoms. The odds ratio was interpreted as an approximation of the risk, because the study design enabled this kind of comparison. The reliability of the estimated parameters was checked, and all values for the relative differences were much $<0.01$ (e.g., $4.57 \times 10^{-7}$ and $\left.2.23 \times 10^{-8}\right)$, indicating that our estimates were reliable. Age, sex, and maternal education were considered a priori confounders. Confounding was investigated using a forward stepwise strategy, and variables were considered to be present when the measurement of association of the complete model and that of the reduced model differed by $10 \%$ or more. A likelihood ratio test was performed to compare the models with and without the interaction term to evaluate the role of atopy in the relationship between the psychologic components and remission of asthma symptoms. The STATA software program, version 9.0 StataCorp LP. Texas, USA, was used for data analysis.

\section{Ethical considerations}

This study received ethical approval from the International ethics committee of the Institute of collective Health at the Federal University of Bahia and the authorities of the
Brazilian Ministry of Health (Registration number: 047-05/ CEP-ISC FR-78168). Written informed consent was obtained from the legal guardians of each child. The caregivers were informed about all clinically relevant results and also received recommendations from a clinician and were advised to seek help within the public mental healthcare service network.

\section{Results}

From the original cohort of 371 wheezing children at baseline, $229(61.73 \%)$ presented a remission of these symptoms at the second assessment. The mean follow-up time was 630 days (approximately 1 year and 9 months) with a minimum of 491 days (1 year and 4 months) and a maximum of 930 ( 2 years and 7 months). However, only approximately $2 \%$ of the children were followed for more than 2 years (data not shown).

The percentage of remission varied between different subgroups, but it was lower among boys $(60.51 \%)$, those with 4-5 years $(57.14 \%)$, atopic children $(58.52 \%)$ those with severe symptoms at baseline $(46.1 \%)$, children with asthmatic parents $(50.67 \%)$ those with mothers with low levels of education

Table 1 Remission of wheeze during follow-up according to potentially associated factors $(n=371)$

\begin{tabular}{|c|c|c|c|c|c|}
\hline Variables & Total children & Children with remission (\%) & Crude OR & $95 \% \mathrm{Cl}$ & p-Value \\
\hline \multicolumn{6}{|l|}{ Sex } \\
\hline Girls & 176 & $111(63.1)$ & 1 & - & \multirow[t]{2}{*}{0.55} \\
\hline Boys & 195 & $118(60.5)$ & 0.88 & $0.57-1.35$ & \\
\hline \multicolumn{6}{|l|}{ Age } \\
\hline $8-11$ & 117 & $69(58.9)$ & 1 & - & \multirow[t]{3}{*}{0.17} \\
\hline $6-7$ & 149 & $100(67.1)$ & 1.47 & $0.87-2.49$ & \\
\hline $4-5$ & 105 & $60(57.1)$ & 0.91 & $0.52-1.59$ & \\
\hline \multicolumn{6}{|l|}{$\lg E(n=352)$} \\
\hline$<0.70$ & 217 & $134(64.1)$ & 1 & - & \multirow[t]{2}{*}{0.26} \\
\hline$\geq 0.70$ & 135 & 79 (58.5) & 0.77 & $0.49-1.22$ & \\
\hline \multicolumn{6}{|l|}{ Severity of symptoms at baseline } \\
\hline Non-severe symptoms in 2005 & 217 & $158(72.8)$ & 1 & - & \multirow[t]{2}{*}{$<0.0001$} \\
\hline Severe symptoms in 2005 & 154 & $71(46.1)$ & 0.32 & $0.21-0.50$ & \\
\hline \multicolumn{6}{|l|}{ Parental asthma $(n=368)$} \\
\hline No & 293 & $190(64.8)$ & 1 & - & \multirow[t]{2}{*}{0.024} \\
\hline Yes & 75 & $38(50.7)$ & 0.54 & $0.32-0.92$ & \\
\hline \multicolumn{6}{|l|}{ Mother education } \\
\hline Complete secondary or higher & 105 & $71(67.6)$ & 1 & - & \multirow[t]{3}{*}{0.39} \\
\hline Incomplete secondary & 170 & $103(60.6)$ & 0.76 & $0.45-1.29$ & \\
\hline Illiterate or primary & 96 & $55(57.3)$ & 0.67 & $0.37-1.21$ & \\
\hline \multicolumn{6}{|l|}{ Monthly income $(n=356)$} \\
\hline More than $£ 101$ & 175 & $104(59.4)$ & 1 & - & \multirow[t]{2}{*}{0.34} \\
\hline Less than $£ 100$ & 181 & $116(64.1)$ & 1.24 & $0.79-1.93$ & \\
\hline \multicolumn{6}{|l|}{ Someone smoking } \\
\hline No & 266 & $163(61.3)$ & 1 & - & \multirow[t]{2}{*}{0.68} \\
\hline Yes & 104 & $65(62.5)$ & 1.10 & $0.67-1.81$ & \\
\hline \multicolumn{6}{|l|}{ Sanitary conditions } \\
\hline No open sewage & 307 & $194(63.2)$ & 1 & - & \multirow[t]{2}{*}{0.36} \\
\hline Open sewage & 62 & $35(56.4)$ & 0.76 & $0.43-1.35$ & \\
\hline Total & 371 & $229(61.7)$ & & & \\
\hline
\end{tabular}

OR, odds ratio. 
$(57.29 \%)$, and among those who live in an area with open sewage $(56.45 \%)$. However, there was only evidence of an effect in reducing the chances of remission of wheezing for the severity of symptoms at baseline (46.1 vs. 72.8 ; OR $=0.32$; $95 \%$ CI $0.21-0.50 ; \mathrm{p}<0.0001)$ and reported parental asthma (64.9 vs. $50.7 ; \quad \mathrm{OR}=0.54 ; 95 \%$ CI $0.32-0.92 ; \mathrm{p}=0.024$; Table 1).

Overall, the chances of remitting wheeze were much lower among children with any behavioral problems $(56.52 \%$, $53.97 \%$ and $54.35 \%$ ) than among those with no problem at all $(71.52 \%)$. Furthermore, after adjusting for sex, age, maternal education, parental asthma, severity of symptoms at baseline, and follow-up period, there remained strong evidence of an association between internalizing symptoms (mainly depression and anxiety) and a decreased chance of wheezing remission $(\mathrm{AOR}=0.47,95 \%$ CI $0.25-0.94, \mathrm{p}=0.03)$. Similarly, the same was observed for the presence of internalizing, externalizing, and total problems together compared to children with no problems (AOR $=0.51,95 \%$ CI $0.28-0.94$, $\mathrm{p}=0.028)$. Externalizing behavioral problems alone showed no evidence of an effect of on the remission of wheeze (Table 2).

After adjustment for age, sex, maternal education, and follow-up time, there remained good evidence of an association between internalization $(\mathrm{AOR}=0.52,95 \%$ CI $0.29-0.92$, $\mathrm{p}=0.02)$, externalization $(\mathrm{AOR}=0.49,95 \%$ CI $0.27-0.87$, $\mathrm{p}=0.01)$, total behavior problems $(\mathrm{AOR}=0.38,95 \% \mathrm{CI}$ $0.21-0.68, \quad p=0.0007)$, and the remission of non-atopic wheezing (Table 3 ). In spite of the ORs were always below 1 , there was no evidence of an association between those psychologic characteristics of the children and the remission of atopic wheeze.

In addition, we investigated the acquisition of severe symptoms of wheeze during the follow-up among those children which persistent wheeze. From those with non-severe symptoms at baseline (216), 19 of them (8.8\%) acquired severe symptoms during follow-up. We found that children with internalizing problems had almost five times the risk of acquiring severe symptoms, even after taking into account the effect of all potential confounders $(\mathrm{AOR}=4.88,95 \% \mathrm{CI}$ $1.32-17.96, p=0.017)$. There was no effect of externalizing problems or total problems on the risk of developing severe symptoms (Table 4).
Table 3 Remission of atopic and non-atopic wheeze according to behavior problems $(n=352)$

\begin{tabular}{lllll}
\hline \multicolumn{5}{c}{ Remission of Wheeze } \\
\cline { 2 - 5 } Behavior problems & $\begin{array}{l}\text { Children with } \\
\text { remission (\%) }\end{array}$ & AOR* & $95 \% \mathrm{Cl}$ & $\mathrm{p}$-Value \\
\hline Non-atopic children & $(\mathrm{IgE}<0.70)$ & & & \\
Internalization & $51(55.4)$ & 0.52 & $0.29-0.92$ & 0.02 \\
Externalization & $44(53.7)$ & 0.49 & $0.27-0.87$ & 0.01 \\
Any Problem & $49(51.6)$ & 0.38 & $0.21-0.68$ & 0.001 \\
Atopic children (IgE $\geq 0.70)$ & & & \\
Internalization & $30(52.6)$ & 0.66 & $0.33-1.32$ & 0.23 \\
Externalization & $28(54.9)$ & 0.79 & $0.39-1.60$ & 0.50 \\
Any Problem & $32(55.2)$ & 0.78 & $0.39-1.57$ & 0.47 \\
\hline
\end{tabular}

p-Values for interactions between type of behavioral problem and atopy were 0.6 (internalization), 0.52 (externalization), and 0.26 (any problem).

*Adjusted odds ratio: Adjusted by sex, age, maternal education, parental asthma, and follow-up period.

\section{Discussion}

Our findings add to the literature in four important ways. First, to our knowledge, this is the first prospective study to show a consistent effect of behavioral problems on two important outcomes in asthma prognosis simultaneously: remission and progression to severity. Moreover, it approaches the exposures independently, showing that the effect of behavioral problems in asthma is explained by internalizing problems (mainly depression and anxiety) and not to other psychologic symptoms. Third, this observed effect remained significant after adjustment for a number of important confounders and pathway variables. And last, these are the first data from a relatively large urban cohort in a developing setting.

The results of this prospective study of children with wheezing followed for a period of time indicate that the main risk factors for the non-remission of wheeze were the severity of the symptoms at baseline, parental asthma, and the presence of behavioral problems, especially internalization (anxiety/ depression, withdrawal, and somatic complaints). We also found that the risk of developing severe symptoms during the follow-up was almost five times higher among children with

Table 2 Crude and adjusted association between type and presence of behavior problems and the remission of wheeze $(n=371)$

\begin{tabular}{|c|c|c|c|c|c|c|}
\hline \multirow[b]{2}{*}{ Behavior problems } & \multirow[b]{2}{*}{ Total children } & \multicolumn{5}{|l|}{ Remission of wheeze } \\
\hline & & Children with remission (\%) & OR $(95 \% \mathrm{Cl})$ & p-Value & $\mathrm{AOR}^{*}(95 \% \mathrm{Cl})$ & $\mathrm{p}$-Value \\
\hline No problems et all & 165 & $118(71.52)$ & $1(-)$ & - & $1(-)$ & - \\
\hline Externalization & 46 & $26(56.52)$ & $0.51(0.25-1.03)$ & 0.062 & $0.65(0.30-1.39)$ & 0.27 \\
\hline Internalization & 63 & $34(53.97)$ & $0.42(0.22-0.78)$ & 0.007 & $0.47(0.25-0.94)$ & 0.03 \\
\hline I + E + Other Problems & 92 & $50(54.35)$ & $0.46(0.26-0.80)$ & 0.006 & $0.51(0.28-0.93)$ & 0.028 \\
\hline Total & 366 & $228(62.3)$ & & & & \\
\hline
\end{tabular}

AOR, adjusted odds ratio; E, externalization; I, internalization; OR, odds ratio.

*Adjusted by sex, age, maternal education, parental asthma, severity of symptoms at baseline, and follow-up period. 
Table 4 Crude and adjusted association between behavior problems and the progression to severity of wheeze among children with mild symptoms at baseline $(n=217)$

\begin{tabular}{|c|c|c|c|c|c|c|}
\hline \multirow[b]{2}{*}{ Behavior problems } & \multicolumn{6}{|c|}{ Acquisition of severe symptoms } \\
\hline & $\begin{array}{l}\text { Total children with } \\
\text { mild symptoms }\end{array}$ & $\begin{array}{l}\text { Children acquiring } \\
\text { severe symptoms (\%) }\end{array}$ & OR $(95 \% \mathrm{Cl})$ & p-Value & AOR* (95\% Cl) & p-Value \\
\hline No problems et all & 111 & $6(5.41)$ & $1(-)$ & - & $1(-)$ & - \\
\hline Externalization & 26 & $1(3.85)$ & $0.72(0.80-6.41)$ & 0.77 & $1.07(0.11-10.53)$ & 0.95 \\
\hline Internalization & 34 & 7 (21.59) & $4.87(1.42-16.63)$ & 0.01 & $4.88(1.32-17.96)$ & 0.017 \\
\hline$I+E+$ Other Problems & 45 & $5(11.11)$ & $2.12(0.59-7.64)$ & 0.25 & $3.28(0.81-13.36)$ & 0.09 \\
\hline Total & 216 & $19(8.80)$ & & & & \\
\hline
\end{tabular}

AOR, adjusted odds ratio; E, Externalization; I, Internalization; OR, odds ratio.

*Adjusted by sex, age, maternal education, parental asthma, and follow-up period.

internalizing symptoms, compared to those with no psychologic problems.

The presence of behavioral problems and, more specifically, internalization can affect the remission and course of asthma through two different mechanisms. First, chronic stress or other chronic psychologic conditions may contribute to greater asthma morbidity via autonomic $(6,23)$ and inflammatory pathways (24-26). Evidence exist that in predisposed individuals experiencing chronic stress, the HPA axis become unresponsive to the ACTH stimulation, leading to exacerbation of inflammation $(15,25-27)$. Secondly, it is also known that there are several issues relating the management of chronic conditions in children with behavior problems. Children with internalization symptoms have limited asthma problem-solving skills and adhere less to treatment schemes (13).

In this study, we identify that the effect of the psychologic characteristics of the child on the remission of symptoms seems to be present only for those with non-atopic wheezing. Although our study is underpowered to find evidence of an interaction, we believe that this result is in accordance with the recent findings that show that in Latin America, the effect of psychosocial factors is more relevant to non-atopic asthma than to atopic asthma $(17,28-30)$.

Non-differential misclassification of the outcome could potentially be possible, because of the choice of the question 'wheeze in the previous 12 months' as a measure to assess the presence/absence of asthma symptoms rather than medical diagnosis. However, although we are aware that not all wheezing is necessarily asthma, we opted to use this simpler measure as there is an absence of a widely agreed definition of asthma to be used in epidemiological studies $(31,32)$. Furthermore, the validation study in Brazil showed that the question 'wheezing in the last 12 months' had good sensitivity and specificity in identifying asthma cases, making it the best definition available for a community-based study where access to health services is limited and the use of medical diagnosis would have been difficult (3). Follow-up bias is unlikely as no systematic difference was found when comparing the group of children who were followed with the group of children who dropped out. Another potential limitation is the absence of information regarding the effect of treatment on the remission of asthma symptoms. However, in this population, medication for asthma is reported to be highly underused (33) and only one child reported the use of inhaled corticosteroids. Therefore, it was not possible to analyze the data regarding medication. Also, the psychologic evaluation was performed once, during baseline and it is possible that some psychologic changes may have happened during the follow-up.

Despite these limitations, this study consistently showed an important effect of internalizing problems in: (i) reducing the risk of remission of asthma symptoms and (ii) increasing the risk of progressing to severe symptoms. The contribution of this study for understanding the course of asthma symptoms is relevant specially for presenting data from a poor urban population in Latin America, where there is a high burden of asthma and no integrated management strategy. By consistently showing the role of internalization problems in asthma morbidity, these results highlight important aspects that should be taken into account when planning and implementing public policies for the management of childhood asthma. Asthma control programs should also provide psychologic care as part of the health support for children with asthma to improve overall psychologic and physical health conditions of the child, possibly increasing the remission of symptoms and reducing the chance of a worse course of the condition.

\section{Acknowledgments}

This research is supported by The Wellcome Trust Latin American Centres of Excellence Programme, Grant No. 074679/Z/04/Z, at the Institute of Collective Health as part of the SCAALA Programme.

\section{References}

1. Pearce N, Ait-Khaled N, Beasley R, et al. Worldwide trends in the prevalence of asthma symptoms: phase III of the International Study of Asthma and Allergies in Childhood (ISAAC). Thorax 2007: 62: 758-66.
2. Pearce N, Douwes J. The global epidemiology of asthma in children. Int $J$ Tuberc Lung Dis 2006: 10: 125-32.

3. Sole D, Wandalsen GF, Camelo-Nunes IC, Naspitz CK. Prevalence of symptoms of asthma, rhinitis, and atopic eczema among
Brazilian children and adolescents identified by the International Study of Asthma and Allergies in Childhood (ISAAC) - Phase 3. $J$ Pediatr (Rio J) 2006: 82: 341-6.

4. Santos LA, Oliveira SM, Santoro IL, Fernandes ALG. Direct costs of asthma in 
Brazil: a comparison between controlled and uncontrolled asthmatic patients. Braz J Med Biol Res 2007: 40: 943-8.

5. Haczku A, Panettieri RA Jr. Social stress and asthma: the role of corticosteroid insensitivity. J Allergy Clin Immunol 2010: 125: $550-8$.

6. Wright RJ, Finn P, Contreras JP, et al. Chronic caregiver stress and $\operatorname{IgE}$ expression, allergen-induced proliferation, and cytokine profiles in a birth cohort predisposed to atopy. J Allergy Clin Immunol 2004: 113: 1051-7.

7. Yonas MA, Lange NE, Celedón JC. Psychosocial stress and asthma morbidity. Curr Opin Allergy Clin Immunol 2012: 12: 202-10.

8. Klinnert MD, Nelson HS, Price MR, Adinoff AD, Leung DY, Mrazek DA. Onset and persistence of childhood asthma: predictors from infancy. Pediatrics 2001: 108: E69.

9. Fritz GK, Overholser JC. Patterns of response to childhood asthma. Psychosom Med 1989: 51: 347-55.

10. Creer TL, Bender BG. Asthma. In: Gatchel RJ, Blanchard EB, eds. Psychophysiological Disorders. Washington, DC: APA, 1993: 151-203.

11. Richardson LP, Lozano P, Russo J, Bush T, Katon W. Asthma symptom burden: relationship to asthma severity and anxiety and depression symptoms. Pediatrics 2006: 118: $1042-51$.

12. Dirks JF, Kinsman RA, Horton DJ, Fross KH, Jones NF. Panic-fear in asthma: rehospitalization following intensive longterm treatment. Psychosom Med 1978: 40: 513.

13. Weil CM, Wade SL, Bauman LJ, Lynn $\mathrm{H}$, Mitchell H, Lavigne J. The relationship between psychosocial factors and asthma morbidity in inner-city children with asthma. Pediatrics 1999: 104: $1274-80$.

14. Strunk RC, Mrazek DA, Wolfson GS, et al. Physiological and psychological characteristics associated with deaths from asthma in childhood: a case-controlled study. JAMA 1985: 254: 1193-8.

15. Wright RJ, Rodriguez M, Cohen S. Review of psychosocial stress and asthma: an integrated biopsychosocial approach. Thorax 1998: 53: 1066-74.

16. Cooper PJ, Rodrigues LC, Cruz AA, Barreto ML. Asthma in Latin America: a public heath challenge and research opportunity. Allergy 2009: 64: 5-17.

17. Cooper PJ, Rodrigues LC, Barreto ML. Influence of poverty and infection on asthma in Latin America. Curr Opin Allergy Clin Immunol 2012: 12: 171-8.

18. Barreto ML, Cunha SS, Alcântara-Neves N, et al. Risk factors and immunological pathways for asthma and other allergic diseases in children: background and methodology of a longitudinal study in a large urban center in Northeastern Brazil (Salvador-SCAALA study). BMC Pulm Med 2006: 6: 15.

19. Simões SM, Cunha SS, Barreto ML, Cruz AA. Distribution of severity of asthma in childhood. $J$ Pediatr 2010: 86: 417-23.

20. Achenbach TM. Multicultural evidencebased assessment of child and adolescent psychopathology. Transcult Psychiatry 2010: 47: 707-26.

21. Achenbach TM, ed. Manual for the Child Behavior Checklist/4-18 and 1991 Profile. Burlington, VT: Department of Psychiatry, University of Vermont, 1991

22. Bordin IAS, Mari JJ, Caeiro MF. Validation of the Brazilian version of the Child Behavior Checklist (CBCL)/ Validaçao da versao brasileira do "Child Behavior Checklist” (CBCL) (Invent rio de Comportamentos da Infância e Adolescência): dados preliminares Rev ABPAPAL 1995: 17: 55-66.

23. Calam R, Gregg L, Simpson A, Simpson B, Woodcock A, Custovic A. Behavior Problems Antecede the Development of Wheeze in Childhood: a Birth Cohort
Study. Am J Respir Crit Care Med 2005: 171: $323-7$.

24. Rietveld S, Everaerd W, Creer TL. Stressinduced asthma: a review of research and potential mechanisms. Clin Exp Allergy 2000: 30: 1058-66.

25. Chen E, Fisher EB, Bacharier LB, Strunk RC. Socioeconomic status, stress, and immune markers in adolescents with asthma. Psychosom Med 2003: 65: 984-92.

26. Sternberg EM. Neuroendocrine regulation of autoimmune/inflammatory disease. $J$ Endocrinol 2001: 169: 429-35.

27. Sandberg S, Paton JY, Ahola S, et al. The role of acute and chronic stress in asthma attacks in children. Lancet 2000: 356: 982-7.

28. Santos LM, Santos DN, Rodrigues LC, Barreto ML. Maternal Mental health and social support: effect on childhood atopic and non-atopic asthma symptoms. J Epidemiol Community Health 2012: 66: 1011-6.

29. Barreto do Carmo MB, Neves Santos D, Alves Ferreira Amorim LD, et al. Minor psychiatric disorders in mothers and asthma in children. Soc Psychiatry Psychiatr Epidemiol 2009: 44: 416-20.

30. Feitosa CA, Santos DN, Barreto do Carmo $\mathrm{MB}$, et al. Behavior problems and prevalence of asthma symptoms among Brazilian children. J Psychosom Res 2011: 71: 160-5.

31. Moncayo A-L, Cooper JP. Definitions are important and not all wheeze is asthma. Thorax 2011: 66: 633-4.

32. Asher MI, Montefort S, Bjorksten B, et al. Worldwide time trends in the prevalence of symptoms of asthma, allergic rhinoconjunctivitis, and eczema in childhood: ISAAC Phases One and Three repeat multicountry cross-sectional surveys. Lancet 2006: 368: 733-43.

33. Santos DB, Cruz AA, Simões SDM, et al. Pattern of asthma medication use among children from a large urban center in Brazil. Eur J Clin Pharmacol 2012: 68: 73-82. 